Bangladesh J. Bot. 47(4): 823-829, 2018 (December)

\title{
ELIMINATION OF MICROCYSTIS AERUGINOSA KÜTZ. BY MODIFIED WALNUT AND PEANUT SHELLS WITH PHOSPHORIC ACID
}

\author{
HongQiang Wang, Lieyu Zhang ${ }^{1}$ and Hong LiU \\ School of Resource \& Environment and Safety Engineering, University of South China, \\ Hengyang, Hunan province 421001, PR China \\ Keywords: Microcystis aeruginosa, Walnut shell, Peanut shell, Phosphoric acid, \\ Orthogonal design
}

\begin{abstract}
The phosphoric acid modified walnut and peanut shell were prepared and applied for the removal of the blue-green alga (Microcystis aeruginosa Kütz.). Orthogonal experiment was used to optimize the modified condition. For the efficient removal, $0.05 \mathrm{~g}$ of the modified walnut and peanut shell was added into $50 \mathrm{ml}$ of algal culture and kept standing for 4 hrs. This condition was found best and under which the removal rate of algae can be reached $>90 \%$. At the same time, a comparison between unmodified walnut and peanut shell and modified walnut and peanut shell on the removal of $M$. aeruginosa cells showed that, unmodified walnut and peanut shell have a removal rate of 31.51 and $29.90 \%$, respectively. On the other hand, the modified walnut and peanut shell showed a removal rate of 96.55 and $93.75 \%$, respectively. Walnut and peanut shells modified with phosphoric acid enhanced the removal efficiency of $M$. aeruginosa cells. So, the modified walnut and peanut shell were considered as a potential algaecide with high efficiency of obnoxious algae removal from the environment safely.
\end{abstract}

\section{Introduction}

Algae are ubiquitous in rivers, lakes, dams and reservoirs (Aktas et al. 2012). Very rapid growth of algae can therefore pose a serious threat to the water supply industry, commercial fisheries and aquaculture, human health and coastal aesthetics (Beaulieu et al. 2005, Jiang and Kim 2008). In particular, cyanobacteria may produce toxic secondary metabolites, the cyanotoxins. The production of cyanotoxins has been the object of scientific attention and concern because of associated public health and environmental hazards, including economical losses and environmental impairment (Beaulieu et al. 2005).

To minimize the threat, some studies on removal of cyanobacteria were conducted (Jiang et al. 2010, Pei et al. 2016, Gao et al. 2017). It has been concluded that chemical coagulationflocculation is the most economical step in the water treatment process for the removal of algae (Chen et al. 2009, Wu et al. 2011). For example, cations, namely aluminum ions, ferric ions and synthetic polymers such as polyacrylamide, were shown to flocculate algal cells and form flocs (Dong et al. 2014). However, chemical reagents may not be environmental friendly or cost effective when used in large quantities in natural waters (Zou et al. 2006).

In recent years, extensive attention has been given to research and application of natural algicide, because they are natural low-cost products and characterized by their environmentally friendly behavior.

Under the above background, the modified walnut and peanut shell have been prepared using phosphoric acid as modification reagents to investigate its applicability to remove the cells of Microcystis aeruginosa Kütz. (Microcystaceae).

*Author for correspondence: <whongq77@qq.com>. ${ }^{1}$ Chinese Research Academy of Environmental Sciences, No. 8 Dayangfang Beiyuan Road, Chaoyang, Beijing 100012, China. 


\section{Materials and Methods}

Microcystis aeruginosa which was a common bloom forming species in eutrophic surface water was selected for this study. Culture of $M$. aeruginosa was received from the Institute of Hydrobiology, Chinese Academy of Sciences and was cultured in sterilized BG11 medium (pH 7.4) at $25^{\circ} \mathrm{C}$ with light intensity of 2500 lux (12:12 hrs light: dark cycle). The growth medium of all cultures was BG11 (Rippka et al. 1979).

Walnut (fruit of Juglans regia L., Juglandaceae) and peanut (fruit of Arachis hypogaea L., Fabaceae) shells were initially washed free of debris with tap water and then with deionized water. The materials thus prepared were then dried on trays in an oven at $80^{\circ} \mathrm{C}$ for $6 \mathrm{hrs}$. After drying, the walnut and peanut shells were weighed and powdered to obtain 80-mesh particles.

An appropriate amount of the powdered sample was soaked with deionized water for $48 \mathrm{hrs}$ at room temperature and then filtered with qualitative filter paper $(10$ - $15 \mu \mathrm{m}$ pore diameter, Newstar, 103 type) to remove the suspended substances. The substances on the filter were dried at $95^{\circ} \mathrm{C}$ in oven, then stored in dryers until being used for modification process.

Since the effects of phosphoric acid (PA) volume, reaction time and concentration of PA were high on modified walnut and peanut shell, those were standardized for the experiment. The three levels per factor were used with PA volume 35, 50 and $65 \mathrm{ml}$, the reaction time $0.5,1.5$ and 2.5 hrs and the concentration of PA 0.5, 1.0 and $1.5 \mathrm{~mol} / \mathrm{l}$, respectively (Table 1$)$. Nine reacting conditions were designed according to the orthogonal test as $\mathrm{L}_{9}\left(3^{4}\right)$ (Tables 2-3).

Table 1. Factors and levels of orthogonal test.

\begin{tabular}{lccc}
\hline \multirow{2}{*}{ Levels } & \multicolumn{3}{c}{ Factors } \\
\cline { 2 - 4 } & $\begin{array}{c}\text { (A) Volume of PA } \\
(\mathrm{ml})\end{array}$ & $\begin{array}{c}\text { (B) Concentration of PA } \\
(\mathrm{mol} / \mathrm{l})\end{array}$ & $\begin{array}{c}\text { (C) Reaction time } \\
(\mathrm{hr})\end{array}$ \\
\hline 1 & 35 & 0.5 & 0.5 \\
2 & 50 & 1.0 & 1.5 \\
3 & 65 & 1.5 & 2.5 \\
\hline
\end{tabular}

In $35-65 \mathrm{ml}$ of $0.5-1.5 \mathrm{~mol} / \mathrm{l}$ phosphoric acid solution, $5 \mathrm{~g}$ of the preprocessed walnut and peanut shell were dispersed. The mixtures were stirred vigorously for a certain time. The liquid portion of mixtures was removed by centrifugation. Then the modified walnut and peanut shell were washed at $\mathrm{pH}>5$ with distilled water, followed by drying at $50^{\circ} \mathrm{C}$ in an oven.

The capacity of the modified walnut and peanut shell to remove harmful algal blooms (HABs) was tested using $M$. aeruginosa. The modified walnut and peanut shell were added into $50 \mathrm{ml}$ of algal culture in a $100 \mathrm{ml}$ beaker and kept standing for $4 \mathrm{hrs}$. In control groups, the modified walnut and peanut were not added. At the end of the settling period, a sample was collected $2 \mathrm{~cm}$ below the surface for analysis. Each experiment was done in triplicate.

M. aeruginosa cells were harvested by centrifugation (at $12000 \mathrm{rpm}$ ) and then suspended in $0.5 \% \mathrm{NaCl}$ solution in order to keep the cells alive. The initial cell concentration for all flocculation experiments carried out was controlled at optical density of $0.100-0.150$ at the wavelength of $680 \mathrm{~nm}\left(\mathrm{OD}_{680 \mathrm{~nm}}\right)$ (Clesceri et al. 1999). Concentration of chlorophyll $a$ (chl $a$ ) calibrated against the direct microscopic cell counts (Clesceri et al. 1999) was used to monitor the concentration change of $M$. aeruginosa cells during the flocculation experiment. Samples of $M$. aeruginosa cells filtrated onto $0.45 \mu \mathrm{m}$ glass fiber filters (Whatman Maidstone, UK) were completely dissolved in $5 \mathrm{ml}$ of $90 \%$ acetone solution and then measured for optical density at the wavelength of $665 \mathrm{~nm}\left(\mathrm{~A}_{665} \mathrm{~nm}\right)$. The chlorophyll $a$ concentration was calculated as chl $a \mathrm{mg} / \mathrm{l}=$ $13.4 \times \mathrm{A}_{665 \mathrm{~nm}}$ (Clesceri et al. 1999). 
The clearance of algae (r\%) of every sample based on the chl $a$ concentration was determined after the 4 hrs exposure by the following formula:

$$
r=\frac{T_{2}-T_{1}}{T_{2}} \times 100 \%
$$

where $T_{1}$ and $T_{2}$ were the chl $a$ concentrations of the algae and the control after the flocculation, respectively.

All experiments were performed in triplicate and the data were reported as the mean $( \pm S d)$. Statistical analyses were performed using SPSS software. A probability level of 0.05 was used to establish the significance $(\mathrm{p}<0.05)$.

\section{Results and Discussion}

The orthogonal experimental protocol and the results are presented in Tables 2 and 3, respectively. The results showed that the removal rate of algae can be up to $>48 \%$ of all modified walnut and peanut shells. In order to find the optimum combination, the analysis of range was done by calculating the difference between the maximum and the minimum of the averages for each factor (Ren 2003). For the modified walnut shell, the order of factors was as follows: reaction time $>$ concentration of $\mathrm{PA}>$ volume of $\mathrm{PA}$. The optimum combination was $\mathrm{A}_{2} \mathrm{~B}_{3} \mathrm{C}_{3}$, that is to say,

Table 2. Analysis on results of orthogonal test of modified walnut shell with phosphoric acid.

\begin{tabular}{cccccc}
\hline $\begin{array}{c}\text { Processing } \\
\text { number }\end{array}$ & A & B & C & $\begin{array}{c}\text { D } \\
\text { (null line) }\end{array}$ & $\begin{array}{c}\text { Removal efficiency of } \\
\text { algae (\%) }\end{array}$ \\
\hline 1 & 35 & 0.5 & 0.5 & 1 & 84.93 \\
2 & 35 & 1 & 1.5 & 2 & 48.97 \\
3 & 35 & 1.5 & 2.5 & 3 & 90.60 \\
4 & 50 & 0.5 & 1.5 & 3 & 61.50 \\
5 & 50 & 1 & 2.5 & 1 & 91.64 \\
6 & 50 & 1.5 & 0.5 & 2 & 80.90 \\
7 & 65 & 0.5 & 2.5 & 2 & 72.62 \\
8 & 65 & 1 & 0.5 & 3 & \\
9 & 65 & 1.5 & 1.5 & 1 & \\
\hline$K_{1}$ & 224.50 & 234.05 & 224.50 & 249.26 & \\
$K_{2}$ & 234.04 & 199.28 & 183.16 & 217.49 & \\
$\frac{K_{3}}{K_{1}}$ & 218.98 & 244.19 & 269.86 & 210.77 & \\
$\frac{K_{2}}{K_{3}}$ & 74.83 & 78.02 & 74.83 & 83.09 & \\
$R$ & 78.01 & 66.43 & 61.05 & 72.50 & \\
\hline & 72.99 & 81.40 & 89.95 & 70.26 & \\
\hline
\end{tabular}

adding $1.5 \mathrm{~mol} / \mathrm{l}$ phosphoric acid solution $50 \mathrm{ml}$ into $5.0 \mathrm{~g}$ walnut shell at room temperature with stirring for 2.5 hrs. For the modified peanut shell, the order of factors is as follows: concentration of $\mathrm{PA}>$ reaction time > volume of PA. The optimum combination was $\mathrm{A}_{3} \mathrm{~B}_{3} \mathrm{C}_{2}$, that is to say, adding $1.5 \mathrm{~mol} / \mathrm{l}$ phosphoric acid solution $65 \mathrm{ml}$ into $5.0 \mathrm{~g}$ peanut shell at room temperature with stirring for 1.5 hrs. 
Table 3. Analysis on results of orthogonal test of modified peanut shell with phosphoric acid.

\begin{tabular}{cccccc}
\hline $\begin{array}{c}\text { Processing } \\
\text { number }\end{array}$ & A & B & C & $\begin{array}{c}\text { D } \\
\text { (null line) }\end{array}$ & $\begin{array}{c}\text { Removal } \\
\text { efficiency of } \\
\text { algae (\%) }\end{array}$ \\
\hline 1 & 35 & 0.5 & 0.5 & 1 & 61.77 \\
2 & 35 & 1 & 1.5 & 2 & 72.55 \\
3 & 35 & 1.5 & 2.5 & 3 & 74.04 \\
4 & 50 & 0.5 & 1.5 & 3 & 72.10 \\
5 & 50 & 1 & 2.5 & 1 & 64.19 \\
6 & 50 & 1.5 & 0.5 & 2 & 85.38 \\
7 & 65 & 0.5 & 2.5 & 2 & 77.62 \\
8 & 65 & 1 & 0.5 & 3 & 88.35 \\
9 & 65 & 1.5 & 1.5 & 1 & \\
\hline$K_{1}$ & 208.36 & 211.49 & 208.5 & 214.77 & \\
$K_{2}$ & 221.67 & 198.09 & 233.46 & 207.49 & \\
$\frac{K_{3}}{K_{1}}$ & 227.78 & 248.23 & 215.85 & 71.59 & \\
$\frac{K_{2}}{2}$ & 69.45 & 70.50 & 69.50 & 78.52 & \\
$\frac{K_{3}}{R}$ & 73.89 & 66.03 & 77.82 & 69.16 & \\
\hline & 75.93 & 82.74 & 71.95 & 9.36 & \\
\hline
\end{tabular}

Figs 1 and 2 showed that after modification with phosphoric acid, walnut and peanut shell, the algae removal efficiency increased up to the two adsorbents dose of $0.05 \mathrm{~g}$. At this dose, the algae removal was 96.55 and $93.75 \%$, respectively. Further increase in the adsorbent's doses reduced the removal of algae. Therefore, the most economic and effective algal removal conditions are as follows: $0.05 \mathrm{~g}$ modified walnut and peanut shell for $50 \mathrm{ml} \mathrm{M}$. aeruginosa culture.

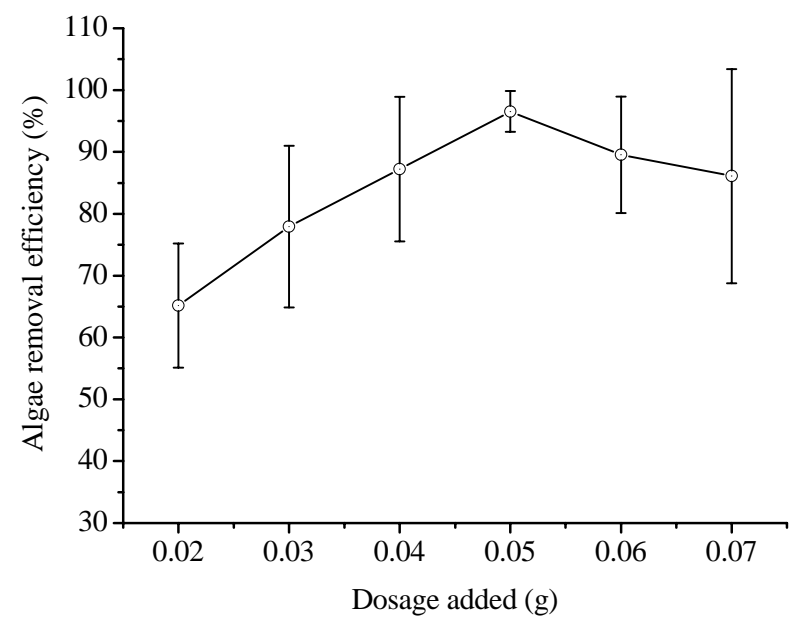

Fig. 1. Effects of the addition of modified walnut shell with phosphoric acid on algae removal. 
A comparison between unmodified walnut and peanut shell and modified walnut and peanut shell on the removal of M. aeruginosa cells is presented in Fig. 3. There were lower efficiency in removal of $M$. aeruginosa with the unmodified walnut and peanut shell, 31.51 and $29.90 \%$ of algae were removed in 4 hrs. In contrast, modified walnut and peanut shell displayed the higher efficiency, with a removal rate of up to 96.55 and $93.75 \%$ in 4 hrs, respectively. An IndependentSamples $\mathrm{T}$ Test was conducted to compare the removal efficiency between unmodified with modified walnut and peanut shells. The statistical study revealed that walnut and peanut shells showed significant differences at unmodified with modified $(p<0.01)$. The results manifested that the modification by phosphoric acid can enhance the removal efficiency of walnut and peanut shell for M. aeruginosa cells.

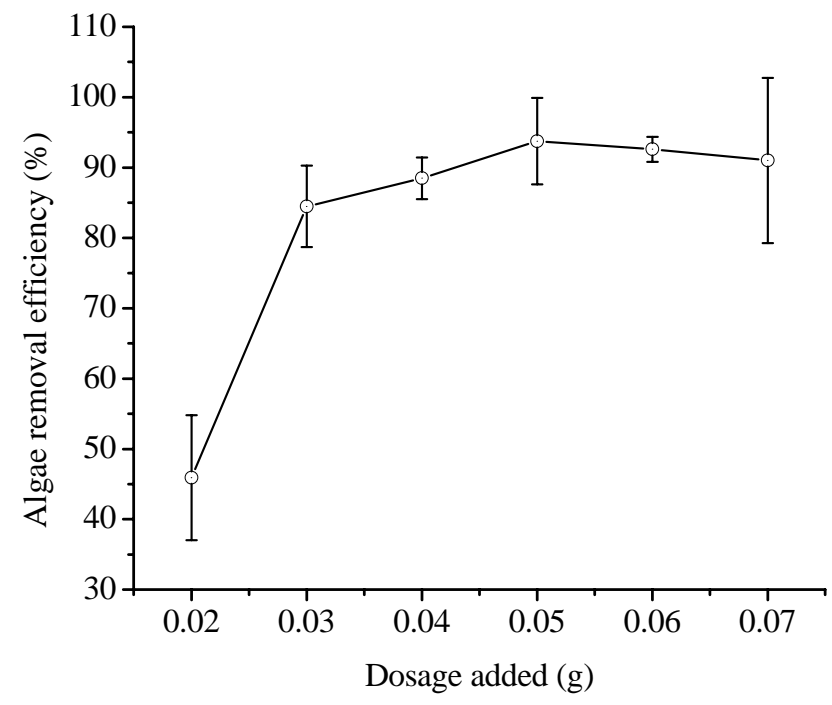

Fig. 2. Effects of the addition of modified peanut shell with phosphoric acid on algae removal.

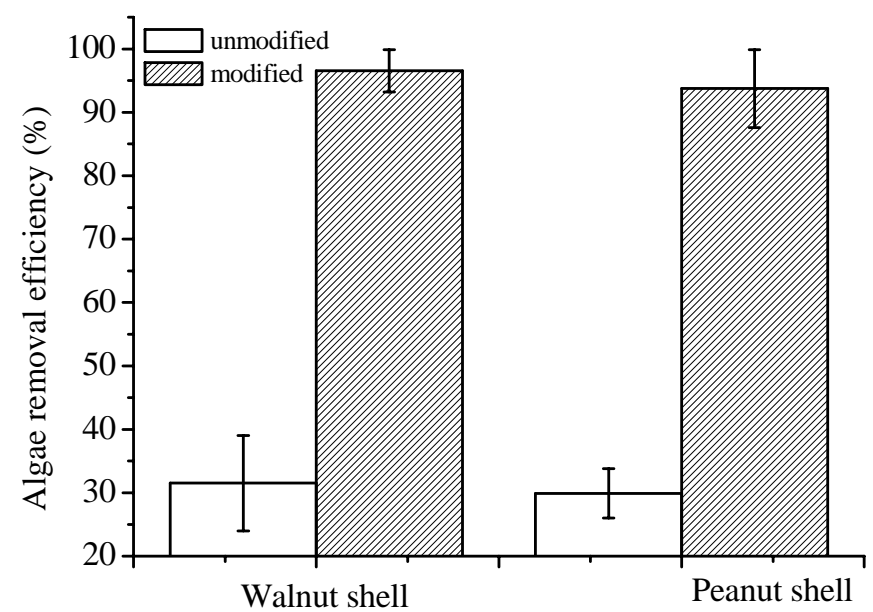

Fig. 3. Effects of unmodified and modified walnut and peanut shell with phosphoric acid on algae removal. 
Liu et al. (1994) and Jia (2012) determined the chemical composition of walnut and peanut shells and found the main components as cellulose and lignin (Table 4). The modified cellulose and lignin have been found effective as excellent metal and basic dye sorbents (Karsheva et al. 2000, O’Connell et al. 2008, Gurgel and Gil 2009, Zhang et al. 2010, Uraki et al. 2006, Gong et al. 2008). Therefore, in the present investigation, the use of modified walnut and peanut shells as algaecides might be due to their high contents of cellulose and lignin.

To increase the adsorption performance modified fiber adsorbent was prepared by esterification (Zhou et al. 2004), halogenation (Tian et al. 2011), oxidation (Mansour et al. 2011) and/or etherification (Li et al. 2012). However, in the current research, walnut and peanut shells were modified with phosphoric acid and used for the removal of $M$. aeruginosa. With this, the removal efficiency was improved dramatically compared to the removal efficiency of unmodified walnut and peanut shell.

Table 4. Chemical composition analysis of walnut and peanut shell.

\begin{tabular}{cccccc}
\hline & $\begin{array}{c}\text { Moisture } \\
(\%)\end{array}$ & $\begin{array}{c}\text { Ash } \\
(\%)\end{array}$ & $\begin{array}{c}\text { Acid-insoluble } \\
\text { lignin (\%) }\end{array}$ & $\begin{array}{c}\text { Cellulose } \\
(\%)\end{array}$ & References \\
\hline Walnut shell & 5.16 & 1.63 & 53.78 & 23.42 & Jia 2012 \\
Peanut shell & 12.27 & 3.30 & 33.55 & 66.36 & Liu 1994 \\
\hline
\end{tabular}

In the present investigation, the best experimental conditions for the orthogonal methods were: adding $50 \mathrm{ml}(1.5 \mathrm{~mol} / \mathrm{l})$ phosphoric acid solution into $5.0 \mathrm{~g}$ walnut shell at room temperature with stirring for $2.5 \mathrm{hrs}$ and adding $65 \mathrm{ml}(1.5 \mathrm{~mol} / \mathrm{l})$ phosphoric acid solution into $5.0 \mathrm{~g}$ peanut shell at room temperature with stirring for $1.5 \mathrm{hrs}$.

\section{Acknowledgements}

This work was supported by the National Natural Science Foundation of China (51108447), the China Postdoctoral Science special Foundation (201104499), the Key Science and Technology Project of Henan Province of China (172102310720), the Key Scientific Research Foundation of the Higher Education Institutions of Henan Province, China (16A610006) and the double first class construct program of USC (2017SYL05).

\section{References}

Aktas TS, Takeda F, Maruo C, Chiba N and Nishimura O 2012. A comparison of zeta potentials and coagulation behaviors of cyanobacteria and algae. Desalin. Water Treat. 48(1-3): 294-301.

Beaulieu SE, Sengco MR and Anderson DM 2005. Using clay to control harmful algal blooms: deposition and resuspension of clay/algal flocs. Harmful Algae 4 (1): 123-138.

Chen JJ, Yeh HH and Tseng I 2009. Effect of ozone and permanganate on algae coagulation removal-pilot and bench scale tests. Chemosphere 74(6): 840-846.

Clesceri LS, Greenberg AE and Eaton AD 1999. Standard Methods for the Examination of Water and Wastewater. American Public Health Association.

Dong CL, Chen W and Liu C 2014. Flocculation of algal cells by amphoteric chitosan-based flocculant. Bioresource Technol. 170: 239-247.

Gao YN, Ge FJ, Zhang LP, He Y, Lu ZY, Zhang YY, Liu BY, Zhou QH and Wu ZB 2017. Enhanced toxicity to the cyanobacterium Microcystis aeruginosa by low-dosage repeated exposure to the allelochemical N-phenyl-1-naphthylamine. Chemosphere 174: 732-738. 
Gong RM, Jin YB and Sun J 2008. Preparation and utilization of rice straw bearing carboxyl groups for removal of basic dyes from aqueous solution. Dyes Pigments 76(2): 519-524.

Gurgel LVA and Gil LF 2009. Adsorption of Cu(II), Cd(II) and Pb(II) from aqueous single metal solutions by succinylated mercerized cellulose modified with triethylenetetramine. Carbohyd. Polym. 77(1): 142-149.

Jia LJ 2012. Research on the performance of ammonia nitrogen removal in wastewater by biological aerated filter using walnut shell as the media. MS Thesis, Shanxi Univ. Sci. Technol. pp. 19.

Jiang C, Wang R and Ma W 2010. The effect of magnetic nanoparticles on Microcystis aeruginosa removal by a composite coagulant. Colloid. Surface. A 369(1-3):260-267.

Jiang JQ and Kim CG 2008. Comparison of Algal Removal by Coagulation with Clays and Al-based Coagulants. Sep. Sci. Technol. 43(7): 1677-1686.

Karsheva MI, Hristov JY and Nenkova SD 2000. Adsorption of lead from aqueous solutions onto technical hydrolyzed lignin. Hung. J. Ind. Chem. 28(2): 151-156.

Li CC, Zhang YW, Peng J, Wu H, Li JQ and Zhai ML 2012. Adsorption of Cr (VI ) using cellulose microsphere-based adsorbent prepared by radiation-induced grafting. Radiat. Phys. Chem. 81(8): 967970.

Liu QM, Xue S and Feng HM 1994. Studies on preparing wood adhesives with whole constituents from the peanut hulls - studies on the constituents of the peanut hulls. J. Nanjing Forestry Univ. 18(1): 72-77.

Mansour MS, Ossman ME and Farag HA 2011. Removal of Cd (II) ion from waste water by adsorption onto polyaniline coated on sawdust. Desalination 272(1): 301-305.

O’Connell DW, Birkinshaw C and O'Dwyer TF 2008. Heavy metal adsorbents prepared from the modification of cellulose: A review. Bioresource Technol. 99(15): 6709-6724.

Pei HY, Xu HZ, Xiao HD, Sun JM, Hu WR, Li XQ, Ma CX and Jin Y 2016. Using a novel hydrogenterminated porous Si wafer to enhance Microcystis aeruginosa effective removal by chitosan at a low dosage. Colloid. Surface. A 499: 88-96.

Ren LQ 2003. Optimum design and analysis of experiments. Version 2. Higher Education Press, Beijing.

Rippka R, Deruelles J, Waterbury JB, Herdman M and Stanier RY 1979. Generic assignments, strain histories and properties of pure cultures of cyanobacteria. J. Gen. Microbiol. 111(1): 1-61.

Tian Y, Wu M, Liu RG, Wang DQ, Lin XB, Liu WL, Ma L, Li YD and Huang Y 2011. Modified native cellulose fibers: A novel efficient adsorbent for both fluoride and arsenic. J. Hazard. Mater. 185(1): 93100.

Uraki Y, Imura T, Kishimoto T and Ubukata M 2006. Body temperature-responsive gels derived from hydroxypropylcellulose bearing lignin. II: Adsorption and release behavior. Cellulose 13(3): 225-234.

Wu C, Xu X, Liang J, Wang Q, Dong Q and Liang W 2011. Enhanced coagulation for treating slightly polluted algae-containing surface water combining polyaluminum chloride (PAC) with diatomite. Desalination 279(1-3): 140-145.

Zhang W, Li CY, Liang M, Geng YM and Lu CH 2010. Preparation of carboxylate-functionalized cellulose via solvent-free mechanochemistry and its characterization as a biosorbent for removal of $\mathrm{Pb}^{2+}$ from aqueous solution. J. Hazard. Mater. 181(1-3): 468-473.

Zhou D, Zhang LN, Zhou JP and Guo SL 2004. Cellulose/chitin beads for adsorption of heavy metals in aqueous solution. Water Res. 38(11): 2643-2650.

Zou H, Pan G, Chen H and Yuan XZ 2006. Removal of cyanobacterial blooms in Taihu Lake using local soils. II. Effective removal of Microcystis aeruginosa using local soils and sediments modified by chitosan. Environ. Pollut. 141(2): 201-205. 